\title{
TINGKAT KECEMASAN PADA ANAK DENGAN KEBERHASILAN PEMASANGAN INFUS
}

\section{ANXIETY LEVEL WITH SUCCESS IN CHILDREN INFUSION SETUP}

\author{
Eka Listianingsih $^{1}$, Desi Kurniawati ${ }^{2}$, Pira Prahmawati ${ }^{3}$ \\ ${ }^{123}$ Fakultas Kesehatan Universitas Muhammadiyah Pringsewu \\ Email: desi_kurniawati04@yahoo.com
}

\begin{abstract}
Anxiety Level With Success In Children Infusion Setup. Medical procedures such as infusions that cause prolonged trauma to children. The most prominent response of children during hospitalization is anxiety. The purpose of this study was to determine the relationship between the level of anxiety in children with infusion in the hospital. Surya Asih Pringsewu in 2019. The research design used in this study was an analytical survey with a cross sectional approach. The population in this study were all pediatric patients who were treated and given intravenous infusion aged 3 to 12 years, the number of samples in the study was 96 people. The sampling technique used was accidental sampling, the data collection tool used an anxiety level observation sheet. The statistical test in this study used the Chi square test. The results showed that there was a relationship between the level of anxiety in children and the success of infusion in the hospital. Surya Asih Pringsewu in 2019, with pvalue $=0.000<\alpha=0.05$. Researchers consider that children should get family attention so that children's anxiety is not excessive and nurses can install infusions with one puncture. In addition, to reduce anxiety in children, health workers can also provide games to children, so that their anxiety levels are reduced
\end{abstract}

Keywords: Keywords: Anxiety Level, Success of Infusion

\begin{abstract}
Abstrak: Tingkat Kecemasan Pada Anak dengan Keberhasilan Pemasangan Infus. Prosedur medis seperti pemasangan infus yang menimbulkan dampak trauma berkepanjangan pada anak. Respon anak selama dirawat di rumah sakit yang paling menonjol adalah kecemasan. Tujuan penelitian ini adalah untuk mengetahui tentang hubungan tingkat kecemasan pada anak dengan tindakan pemasangan infus di RS. Surya Asih Pringsewu tahun 2019. Desain penelitian yang digunakan pada penelitian ini adalah survey analitik dengan pendekatan cross sectional. Populasi dalam penelitian ini adalah seluruh pasien anak yang dirawat dan dilakukan pemasangan infus yang berusia 3 sampai 12 tahun, jumlah sampel dalam penelitian sebanyak 96 orang. Teknik Pengambilan sampel menggunakan accidental sampling, alat pengumpulan data menggunakan lembar observasi tingkat kecemasan. Uji statistik dalam penelitian ini menggunakan uji Chi square. Hasil penelitian menunjukkan bahwa ada hubungan tingkat kecemasan pada anak dengan keberhasilan pemasangan infus di RS. Surya Asih Pringsewu Tahun 2019, dengan $p$-value $=0,000<\alpha=0,05$.Peneliti menilai sebaiknya anak perlu mendapatkan perhatian keluarga agar kecemasan anak tidak berlebihan dan perawat dapat melakukan pemasangan infuse dengan sekali tusuk. Selain itu, untuk mengurangi kecemasan pada anak petugas kesehatan juga dapat memberikan permainan kepada anak, agar tingkat kecemasan yang dimiliki berkurang.
\end{abstract}

Kata kunci: Kata Kunci: Tingkat Kecemasan, Keberhasilan Pemasangan Infus

\section{PENDAHULUAN}

Hospitalisasi merupakan keadaan suatu proses yang karena suatu alasan yang berencana atau darurat, mengharuskan anak untuk tinggal di rumah sakit, menjalani terapi dan perawatan sampai pemulangannya kembali ke rumah (Supartini, 2014).

Respon anak selama dirawat di rumah sakit yang paling menonjol adalah kecemasan. Perasaan yang timbul tersebut jika tanpa intervensi yang tepat dan menyesuaikan tahap perkembangan, sangat 
memungkinkan terjadinya gangguan pertumbuhan dan perkembangan pada anak. Salah satu tanda anak tidak cemas akibat hospitalisasi adalah anak kooperatif ketika dilakukan tindakan keperawatan. Pada saat dirawat dirumah sakit anak akan mengalami berbagai perasaan tidak menyenangkan, seperti marah, takut, cemas, sedih dan nyeri (Stuart, 2013).

Respon anak selama dirawat di rumah sakit yang paling menonjol adalah kecemasan. Perasaan yang timbul tersebut jika tanpa intervensi yang tepat dan menyesuaikan tahap perkembangan, sangat memungkinkan terjadinya gangguan pertumbuhan dan perkembangan pada anak. Salah satu tanda anak tidak cemas akibat hospitalisasi adalah anak kooperatif ketika dilakukan tindakan keperawatan. Pada saat dirawat dirumah sakit anak akan mengalami berbagai perasaan tidak menyenangkan, seperti marah, takut, cemas, sedih dan nyeri (Stuart, 2013).

Berdasarkan pengamatan peneliti terhadap beberapa anak yang dirawat di RS. Surya Asih Pringsewu anak terlihat tidak nyaman dengan lingkungan rumah sakit yang asing, adanya peralatan medis yang menakutkan dan prosedur medis yang menyakitkan membuat anak menjadi cemas. Menindaklanjuti masalah tersebut perawat melakukan asuhan keperawatan secara komprehensif melalui pendekatan proses keperawatan pada pasien anak, yang umumnya memerlukan tindakan medis invasif seperti pemasangan infus (Nursalam, 2013). Beberapa tindakan tersebut dapat membuat anak menjadi trauma. Prosedur medis seperti pemasangan infus yang menimbulkan dampak trauma berkepanjangan pada anak. Terapi intravena (pemasangan infus) yang dilakukan secara invasif dengan menggunakan metode yang efektif untuk memenuhi kebutuhan cairan dan elektrolit dan sebagai tindakan pengobatan serta pemberian makan atau nutrisi (Aziz, 2013).

Upaya untuk mengurangi kecemasan yang dialami pada pasien anak salah satunya melakukan pendekatan dengan cara bermain. Berdasarkan penelitian yang dilakukan oleh Pirnando (2016) yang berjudul pengaruh terapi bermain dokter-dokteran terhadap kecemasan pada anak usia prasekolah saat pemasangan infus diruang Anak di Rumah sakit Wisma Rini Pringsewu dengan jumlah responden 14 anak 7 sebagai kelompok intervensi dan 7 sebagai kelompok kontrol hasilnya adalah ada pengaruh terapi bermain dengan respon cemas anak usia prasekolah di Rumah sakit Wisma Rini Pringsewu tahun 2017 dengan $p$-value $<0.05$. Metode bermain diberikan pada anak yang dirawat agar anak dapat beradaptasi lebih efektif terhadap stres karena penyakit atau dirawat di rumah sakit dan anak mendapatkan ketenangan dalam bermain (Nursalam, 2013).

Tindakan yang dilakukan perawat untuk mencegah dan meminimalisir perlukaan tubuh dan rasa sakit pada anak yang dilakukan pemasangan infus selain menggunakan terapi bermain yaitu dengan cara memberi dukungan pada anggota keluarga, perawat memberikan informasi sehubungan dengan penyakit, prosedur tindakan yang akan dilakukan pada anaknya (Nursalam 2013). Sejalan dengan penelitian yang dilakukkan Cristine (2010) di Rumah Sakit Advent Medan, tentang hubungan antara dukungan keluarga dengan respon cemas anak usia sekolah terhadap pemasangan intravena dengan hasil bahwa ada hubungan antara dukungan keluarga dengan respon cemas anak usia sekolah terhadap pemasangan intravena di Rumah Sakit Advent Medan. Penelitian ini membuktikan bahwa semakin tinggi dukungan keluarga yang diberikan maka semakin rendah respon cemas anak usia sekolah terhadap pemasangan intravena dan sebaliknya semakin rendah dukungan yang diberikan keluarga semakin tinggi respon cemas anak usia sekolah terhadap pemasangan intravena.

Karakteristik anak dalam berespon terhadap nyeri diantaranya dengan menangis keras atau berteriak, mengungkapkan secara verbal, memukul tangan atau kaki, menjauhkan hal yang menyebabkan nyeri, kurang kooperatif, membutuhkan restrain, meminta untuk mengakhiri tindakan yang menyebabkan nyeri, menempel atau berpegangan pada orang tua, perawat atau yang lain, membutuhkan dukungan emosi seperti pelukan, melemah, antisipasi terhadap nyeri aktual (Supartini, 2014). Respon cemas pada anak tersebut mengakibatkan perawat kesulitan dalam melakukan pemasangan infus. Hal tersebut sejalan dengan hasil penelitian dari Efendi (2016) yang berjudul hubungan tingkat kecemasan pada pasien anak dengan keberhasilan pemasangan infus di klinik Pratama Ridho Husada Pesawaran dengan hasil ada hubungan antara tingkat kecemasan pada anak hasil nilai diperoleh p-value 0,043 .

Berdasarkan hasil survey yang dilakukan oleh peneliti di Rumah Sakit Surya Asih Pringsewu diketahui jumlah anak yang dirawat di Rumah Sakit Surya Asih selama 1 tahun 2018 dengan jumlah 
Vol 10 No 2 Juli 2021 | Page 122-126

605. Setiap bulan pasien anak yang dirawat berjumlah 70 pasien. Hasil wawancara dan observasi dengan perawat anak dan kepala ruang anak pada Bulan Maret 2019 didapatkan banyak pasien anak yang mengalami kecemasan pada saat dilakukannya tindakan medis pemasangan infus. Hasil observasi dari 8 anak yang dilakukan pemasangan infus, 5 anak mengalami kecemasan sehingga mengakibatkan terjadinya kegagalan pemasangan infus (RM RS Surya Asih Pringsewu, 2019). Berdasarkan uraian diatas, maka peneliti tertarik untuk melakukan penelitian "Hubungan tingkat kecemasan pada anak dengan keberhasilan pemasangan infus di ruang perawatan dan ruang UGD RS Surya Asih Pringsewu Tahun 2019““

\section{METODE}

Jenis penelitian ini merupakan penelitian survei analitik dengan menggunakan pendekatan cross sectional. Waktu penelitian dilaksanakan pada bulan Mei-Juni 2019 di RS Surya Asih Pringsewu. Populasi dalam penelitian ini adalah seluruh pasien anak yang berusia 3 tahun sampai 12 tahun dan akan di rawat dan dilakukan pemasangan infus. Sampel penelitian ini berjumlah 96 anak. Tehnik pemilihan sampel dalam penelitian ini adalah accidental sampling dan analisis data yang digunakan (chi square)..

\section{HASIL}

Hasil penelitian sebagai berikut:

Tabel 1. Distribusi frekuensi responden berdasarkan jenis kelamin, usia anak, tingkat kecemasan dan pemasangan infuse

\begin{tabular}{ccc}
\hline \multicolumn{1}{c}{ Jenis Kelamin } & Frequency & Percent \\
\hline$-\quad$ Perempuan & 62 & $64.6 \%$ \\
$-\quad$ Laki-laki & 34 & $35.4 \%$ \\
Usia Anak & Frequency & Percent \\
$-\quad$ Todler (1-3 tahun) & 35 & $36.4 \%$ \\
$-\quad$ Pra Sekolah (4-6 tahun) & & \\
$-\quad$ Usia Sekolah (7-12 tahun) & 19 & $19.8 \%$ \\
& & \\
Tingkat Kecemasan & 42 & $43.8 \%$ \\
Tidak Cemas & Frequency & Percent \\
Ringan & 10 & $10.4 \%$ \\
Sedang & 68 & $70.8 \%$ \\
Pemasangan Infus & 18 & $18.8 \%$ \\
1 Kali & Frequency & Percent \\
>1 Kali & 56 & $58.3 \%$ \\
Total & 40 & $41.3 \%$ \\
& $\mathbf{9 6}$ & $\mathbf{1 0 0 \%}$ \\
\hline
\end{tabular}

Berdasarkan tabel 1 didapatkan data responden perempuan, anak usia sekolah, kecemasan ringan dan pemasangan infuse 1 kali memiliki jumlah lebih tinggi disbanding yang lain. 
Vol 10 No 2 Juli 2021 | Page 122-126

Tabel 2. Hubungan tingkat kecemasan pada anak dengan keberhasilan pemasangan infus di RS. Surya Asih Pringsewu Tahun 2019

\begin{tabular}{|c|c|c|c|c|c|c|c|}
\hline \multirow{3}{*}{$\begin{array}{l}\text { Tingkat } \\
\text { kecemasan }\end{array}$} & \multicolumn{4}{|c|}{ Pemasangan infuse } & \multirow[b]{3}{*}{$\mathrm{N}$} & \multirow[b]{3}{*}{$\%$} & \multirow{3}{*}{$\begin{array}{l}\boldsymbol{p} \text {-value } \\
0.000\end{array}$} \\
\hline & \multirow{2}{*}{$\begin{array}{l}1 \text { kali } \\
\mathrm{N}\end{array}$} & \multicolumn{3}{|c|}{$>1$ kali } & & & \\
\hline & & $\%$ & $\mathrm{~N}$ & $\%$ & & & \\
\hline Tidak Cemas & 10 & $10.4 \%$ & 0 & $0 . \%$ & 10 & $10.4 \%$ & \\
\hline Ringan & 43 & $44.8 \%$ & 25 & $26.0 \%$ & 68 & $70.8 \%$ & \\
\hline Sedang & 3 & $3.1 \%$ & 15 & $15.6 \%$ & 18 & $18.8 \%$ & \\
\hline Total & 56 & $58.3 \%$ & 40 & $41.7 \%$ & 96 & $100 \%$ & \\
\hline
\end{tabular}

Berdasarkan tabel 1 didapatkan data terdapat hubungan tingkat kecemasan pada anak dengan keberhasilan pemasangan infuse di RS Surya Asih Pringsewu Tahun 2019 dengan p value 0.000.

\section{PEMBAHASAN}

Berdasarkan hasil analisis diketahui bahwa ada hubungan tingkat kecemasan pada anak dengan keberhasilan pemasangan infus di RS. Surya Asih Pringsewu Tahun 2019, hasil uji statistik dengan chi square $\left(X^{2}\right)$ diperoleh $p$-value $=0,000<\alpha=0,05$ hal ini menyatakan bahwa $\mathrm{H}_{\mathrm{a}}$ diterima dan $\mathrm{H}_{0}$ ditolak.

Prosedur medis seperti pemasangan infus yang menimbulkan dampak trauma berkepanjangan pada anak. Terapi intravena (pemasangan infus) yang dilakukan secara invasif dengan menggunakan metode yang efektif untuk memenuhi kebutuhan cairan dan elektrolit dan sebagai tindakan pengobatan serta pemberian makanatau nutrisi (Aziz, 2015).

Menurut (Supartini, 2014) peralatan medis seperti jarum suntik dan peralatan infus adalah sesuatu yang menakutkan menurut anak. (dzul dkk 2019) Tenaga kesehatan, perilaku petugas kesehatan sering kali menimbulkan trauma pada anak misalnya seorang perawat dan dokter datang menemui pasien untuk melakukan asuhan keperawatan tetapi dengan wajah cemberut, masam, tidak ada sapaan, sebelum dilakukan tindakan anak sudah takut dan tidak mau didekati. Penampilan para staf rumah sakit dengan baju putihnya yang terkesan angker juga menjadi hal yang menakutkan bagi anak.

Hasil penelitian dari Efendi (2016) yang berjudul hubungan tingkat kecemasan pada pasien anak dengan keberhasilan pemasangan infus di klinik Pratama Ridho Husada Pesawaran dengan hasil ada hubungan antara tingkat kecemasan pada anak hasil nilai diperoleh p-value 0,043.

Hasil penelitian ini menunjukkan bahwa terdapat hubungan hubungan tingkat kecemasan pada anak dengan keberhasilan pemasangan infuse. Peneliti menilai sebaiknya anak perlu mendapatkan perhatian keluarga agar kecemasan anak tidak berlebihan dan perawat dapat melakukan pemasangan infuse dengan sekali tusuk. Selain itu, untuk mengurangi kecemasan pada anak petugas kesehatan juga dapat memberikan permainan kepada anak, agar tingkat kecemasan yang dimiliki berkurang.

\section{SIMPULAN}

Berdasarkan hasil penelitian terdapat hubungan tingkat kecemasan pada anak dengan keberhasilan pemasangan infuse di RS Surya Asih Pringsewu Tahun 2019 dengan p value 0.000. 
Vol 10 No 2 Juli 2021 | Page 122-126

\section{SARAN}

Hasil penelitian ini diharapkan dapat dijadikan data dasar dan acuan bagi penelitian selanjutnya untuk melakukan penelitian lain dengan variabel yang berbeda, mengenai hospitalisasi dan dampak perpisahan orangtua dengan kcemasan anak.

\section{DAFTAR PUSTAKA}

Aziz AH, Uliyah M. (2013). Kebutuhan Dasar Manusia Buku Saku Praktikum. Jakarta : EGC

Christine, M. (2010). Hubungan Dukungan Keluarga dengan Respon Cemas Anak Usia Sekolah terhadap Pemasangan Intravena di Rumah Sakit Advent Medan. Skripsi. Medan : Universitas Sumatra Utara

Efendi. M. (2016). Hubungan Tingkat Kecemasan Pada Pasien Anak Dengan Keberhasilan Pemasangan Infus Diklinik Pratama Ridho Husada. Skripsi. Pesawaran : Sekolah Tinggi Ilmu Kesehatan Muhammadiyah.

Hasyim DI., Saputri, N (2019). Pendidikan Kesehatan Tanda Bahaya Bayi Baru Lahir Sebagai Upaya Pencegahan Morbiditas Dan Mortalitas Pada Bayi Baru Lahir. JPMT (Jurnal Pengabdian Masyarakat Teknik). Vol 2, No 1 (2019).

DOI: https://doi.org/10.24853/jpmt.2.1.23-26

Nursalam dkk. (2013). Asuhan Keperawatan Bayi dan Anak. Jakarta : Salemba Medika

Pirnando E. (2017). Pengaruh Terapi Bermain Dokter-dokteran Terhadap Kecemasan Pada Anak Usia Prasekolah Saat pemasangan Infus Diruang Anak Rumah sakit Wisma Rini. Skripsi. Pringsewu : Sekolah Tinggi Ilmu Kesehatan Muhammadiyah.

Stuart, G. W. (2013). Buku Saku Keperawatan Jiwa. Edisi : 5. Jakarta : EGC

Supartini Y. (2014). Buku Ajar Konsep Dasar Keperawatan Anak. Jakarta : EGC

Wijayanti, Y., Saputri, N (2020). Mothers' Knowledge for Following Activities of Children in the Health Care Community. Proceedings of the 1st International Conference on Science, Health, Economics, Education and Technology (ICoSHEET 2019). DOI https://doi.org/10.2991/ahsr.k.200723.117 